Chapter 6

\title{
Targets and Approaches to Control Hepatocellular Carcinoma in Future
}

\author{
Mukherjee Biswajit, \\ Hossain Chowdhury Mobaswar, \\ Bhattacharya Sanchari and Shampa Ghosh \\ Additional information is available at the end of the chapter \\ http://dx.doi.org/10.5772/56867
}

\section{Introduction}

Cancer is uncontrolled proliferation of cells, which results from the loss of proper balance between cell death and cell growth. The transformed phenotypes of cancer cells are caused by the accumulation of mutations in a variety of genes, products of which normally play a role in the biochemical pathways that regulate cell death and cell proliferation. Cancer is a broad term used to define a group of more than 250 different diseases (Roncalli et al. 2010). It is a slow multi-stage, multi-step process (Cammà et al. 2008; Calvisi et al. 2009; Sherman 2011). In the first instance, these cells, derived initially from a normal cell, form a primary tumor which comprises a growth-transformed population of cells. The cells acquire a set of mutations to a set of genes which allow them to divide repeatedly in a way that normal cells cannot (Besaratinia et al. 2009; Calvisi et al. 2009). Histologically, cancer is characterized by several morphological alterations, including changes in tissue architecture, cytological abnormalities of both the nucleus and cytoplasm and the presence of abnormal mitoses. A stepwise several biochemical, genetic and biological alterations eventually result in a cancer.

Primary liver cancer or hepatocellular carcinoma (HCC) is a very common malignant hepatobiliary disease and it represents the fifth most frequent neoplastic disease which causes approximately 1 million deaths per year (Yang and Roberts, 2010, Cha et al. 2010). HCC is the third leading cause of cancer related death worldwide (Raphael 2012). Viruses and chemicals have been identified as the most important etiological factor associated with the development of human liver cancer (Carr et al. 2010). The most common cause of HCC is hepatitis B and C (Woo et al. 2008; Masuzaki et al. 2008, Gouas et al. 2010; Iavarone and Colombo 2011) and a 
number of risk factors that have been identified (Shariff et al. 2009; Sherman 2010; Gomaa et al. 2008 and 2009). Most of HCC cases develop from a cirrhotic liver (Bartolomeo et al. 2011; Chagas et al. 2009; Orlando et al.2009; Cammà et al. 2008) with an annual incidence of 2-6\% for hepatitis B virus carriers (Kew 2010; Lim et al. 2009; Hadziyannis 2011) and 3-5\% for hepatitis C virus-infected patients (Masuzaki et al. 2008; Rosen 2011). Males are more susceptible to HCC.

Despite the advances in cancer treatments there is no effective chemotherapeutic protocol to treat HCC (Andreana et al. 2009; Arii et al. 2010). Advanced HCC has a poor prognosis ( Simile et al. 2011; Sonja et al. 2010). Historically, no effective systemic chemotherapy treatment options have been available for patients with advanced HCC (Bruix and Sherman 2011). Thus, proper understanding of the molecular basis of pathogenesis of HCC can lead us to plan for proper therapeutic strategies to combat the notorious disease.

Accumulating epidemiological evidence suggests that a pronounced predisposition to develop cancer as a consequence of a mutation in a single gene is rare (approximately 1-5\%) (Frau et al. 2010). One possible explanation for this finding is that carcinogenesis is a multistage process involving a number of different genes and environmental factors (Chung et al. 2008; Forner et al. 2010; Frau et al. 2010). In connection with many distinct subtypes of cancer, some functional alterations are required for malignant transformation. They are, namely, sufficiency with respect to growth signals, insensitivity to growth-inhibitory signals, evasion of programmed cell death (apoptosis), the potential for unlimited replication, sustained angiogenesis, tissue invasion and metastasis (Bergers and Hanahan 2008; Bartolomeo et al. 2011; Cao et al. 2010; Frau et al. 2010; Gouas et al. 2010). The exact number of distinct stages involved may vary from tumor to tumor, since some of these acquired characteristics probably interact with other processes (Roncalli 2010). Indeed, the heterogeneity of tumors, both with regards to morphology and pattern of gene expression, may even indicate the participation of many more sequential steps.

A highly regulatory network controls cellular proliferation in multicellular organisms. Normally cells in many tissues and organs remain in a non-proliferative state. In response to external stimuli such as growth factors, hormones or antigens, cells are stimulated to begin DNA synthesis and cellular proliferation according to the need of the living system. As soon as the need is fulfilled, the cell division stops. However, cancerous cells are characterized by the unrestrained cellular proliferation due to the alteration of normal cellular signalling process and they acquire complete or partial independence of mitogenic signals through production of growth factors (Garrett et al. 2008; Hironaka et al. 2009) and /or alteration in number or structure of cellular receptors (Lachenmayer et al. 2010) and/ or modulation in the activity of post receptor signalling pathway (Cavard et al. 2008; Chen et al. 2009). The communication of extracellular signals to the cells, then to the nucleus to modulate gene expression is governed by phosphorylation regulated signal transduction cascades which act to amplify the events generated at the cellular membrane by ligand-receptor interaction or cell stress. Therefore, identification of the extracellular factors that modulate cell proliferation and elucidation of the cellular molecular mechanism during the development of cancer can answer many fundamental questions in cancer cell biology. It is important to understand in details the 
receptors and the signal transduction pathways involved in the pathogenesis of cancer to provide potential target for therapeutic intervention. Many studies have focused to identify molecular pathways to elicit cancer cell proliferation, including HCC. Here many of them have been highlighted to identify fundamental targets of hepatocellular oncogenesis. Thus, the present chapter has been projected to the molecular targets and approaches to intervene the targets for the management of HCC in humans in coming years.

\section{Therapeutic targets for HCC}

Three generally considered fundamental but interrelated targets of controlling oncogenesis are regulation of deregulated energy metabolism and ion homeostasis; signal transduction, oncogenes and growth factors; and immunomodulation. One of the most characteristic phenotypes of rapidly growing cancer cells is their propensity to catabolise glucose at high rates. Rapidly growing activity to cancer cells has a reduced number of mitochondria and increased glycolytic activity with a shift from respiratory to fermentative ATP supply to cover most of their energy requirement. The stimulation of the $\mathrm{K}^{+}, \mathrm{H}^{+}$and $\mathrm{Na}^{+}$fluxes is a general early response in most of the quiescent cells stimulated to proliferate by multiple combinations of growth promoting factors. Growth factors, cytokines exert their action on cell proliferation by modulation of cell signalling process. There is a strong relationship between the immune system and cell proliferation. Immune suppressive agents have a powerful effect on hepatocyte growth regulation in HCC.

Reviewing current literature, a selection of therapeutic targets of HCC has been described below.

Like most other cancers, growth factors, their receptors, and downstream signalling proteins play a pivotal role in the development and maintenance of HCC and are of significant interest for future therapeutic approaches. In foetal liver, a large number of growth factors such as epidermal growth factor (EGF), fibroblast growth factor (FGF), hepatocyte growth factor (HGF), insulin-like growth factors (IGFs), platelet-derived growth factor (PDGF), transforming growth factors- $\alpha$ and $-\beta$ (TGF- $\alpha$, TGF- $\beta$ ), and vascular endothelial growth factor (VEGF) (Höpfner et al. 2008; Hoshida et al. 2008 and 2009) are produced. Their secretion either declines or shuts down in adult liver. However, during hepatic regeneration due to the cause of hepatic injury or damage many such growth factors (Böhm et al. 2010), namely, EGF, TGF- $\alpha$, IGFs, and VEGF are upregulated in normal hepatocytes. The transient upregulation of those factors is dysregulated in the chronic injured liver leading to sustained mitogenic/ oncogenic signalling, during the development of HCC. FGF and PDGF released from non-hepatocyte sources such as activated hepatic stellate cells, myofibroblasts, endothelial cells, Kupffer cells, and bile duct epithelia have been shown to play important roles in promoting hepatic fibrosis and HCC growth (Friedman 2008). The ubiquitin-proteasome pathway has emerged as a key player in the regulation of several diverse cellular processes. Inhibition of poly-ubiquitination using proteasome inhibitors has shown some light in HCC treatment. Besides, immunomodulation has been found to be 
effective in stabilizing HCC growth in patients. Number of immunomodulators has been investigated and few of them have been found to be effective. They have been discussed below under immunomodulation agents. Signal transduction, and growth factors; inhibitors of proteasome pathway, immunomodulation and antisense oligomer-mediated inhibition of targeted oncogenes have been projected as future targets and approaches of HCC (Table 1).

\begin{tabular}{ll}
\hline \multicolumn{1}{c}{ Molecular targets in HCC } & Inhibitors / Modulators / Antisense oligonucleotides \\
\hline Growth factors, e.g., EGFR, EGF, TGF-a, TGF- $\beta$, VEGF & Cetuximab, Gefitinib, Erlotinib, Vandetanib. \\
\hline mTOR & Rapamycin, Temsirolimus, Salirasib, RAD001 \\
\hline Multikinase & Sorafenib, Everolimus, AP23573, RAD001. \\
\hline Proteasome & Bortezomeb \\
\hline Immunomodulators used in HCC & Thymostimulin, Retinoids, Everolimus, Azathioprine, 6- \\
\hline Antisense oligonucleotides used in HCC & mercaptopurine. \\
\hline
\end{tabular}

Table 1. Growth factors, proteasome-inhibitors, immunomodulators and antisense oligomers in HCC

\section{Approaches}

A selection of agents currently in the development and/or testing stages for the clinical application in targeted HCC treatment is summarized in the following section.

\subsection{Therapies against EGFR}

There are two classes of anti-EGFR agents found to have antitumor activity against HCC. One of them belongs to monoclonal antibodies (as an example cetuximab) which competitively inhibit extracellular endogenous ligand binding. The other class belongs to chemicals such as gefitinib, erlotinib which inhibit the intracellular tyrosine kinase domain. EGF, TGF- $\alpha$, heparin binding-EGF and EGFR have been shown to involve in the pathogenesis of HCC. Thus, EGFR signalling pathways have become a potential investigating area of research to identify the target (s) to inhibit proliferation of HCC and metastasis. Gefitinib, erlotinib, cetuximab were tested in patients with advanced HCC (Thomas et al. 2007; Philip et al. 2005; Asnacios et al. 2008; Wu et al. 2011, Levêque 2011) and were reported to possess signals of activity in controlling the progress of HCC in a variable extent.

\subsection{Targeting approaches towards VEGF and VEGFR}

HCCs rely on the formation of new blood vessels for growth, and VEGF is critical in this process (Zhu et al. 2011). HCCs are with high vascular architecture and VEGF is a key factor in tumor angiogenesis (Bergers and Hanahan, 2008; Garrett et al. 2008; Hironaka et al. 2009). Therefore, 
the inhibition of angiogenesis is a potential and promising therapeutic approach in HCC. AntiVEGF therapy with sorafenib was the first systemic therapy against VEGF to demonstrate improved survival in patients with advanced-stage HCC (Cheng et al. 2009; Zhu et al. 2011, Miller et al. 2009; Zhu 2008, Llovet et al. 2008a). Sorafenib was also tested in advanced stage liver cirrhosis patients with unresectable HCC (Pinter et al. 2009). Bevacizumab alone or in combination with other agents showed promise in patients with advanced HCC (Siegel et al. 2008; Thomas et al. 2009; Thomas et al. 2008; Kaseb et al. 2012). However, the common bevacizumab-related side effects were hypertension, bleeding, and proteinuria (Thomas et al. 2009; Siegel et al. 2008a; Kopetz et al. 2009). Besides, inhibition of the tyrosine kinase activity of VEGFR has been tried as an effective measure to inhibit angeogenesis in HCC (Bhide et al. 2010). PTK787/ ZK222584 (vatalanib) is an oral angiogenesis inhibitor that targets tyrosine kinase activity of VEGFR (Gauler et al. 2012). Pan-VEGFR tyrosine kinase activity inhibitor with activity against PDGFRs also carries a new hope.

\subsection{Multi-kinase inhibitor}

Like all other cancers diverse signaling pathways in HCC are very complex. One of the key pathways regulating cellular proliferation is the mitogen activated protein Kinase (MAPK) pathway. Other pathways involved in the development of HCC include the PI3K/Akt/mTOR, hepatocyte growth factor (HGF)/c-MET, insulin-like growth factor (IGF) and its receptor (IGFR) pathways, and the Wnt- $\beta$ catenin pathway (Cavard et al. 2008; Chen et al. 2009; DesboisMouthon et al. 2009; Takigawa and Nouso 2008; Zhang et al. 2008). The Raf family of kinases are central to this pathway where the transduction of extracellular growth signals from the cell surface to the nucleus occurs via the ras-raf-MEK-ERK signaling cascade. The several experiments have shown that Raf, MEK, MAP Kinase are downstream effector molecules of Ras and their sequential order in the pathway. The Raf serine/threonine kinases are the principal effectors of Ras in this mitogen activated protein Kinase (MAPK) signaling pathway. As serine/ threonine kinases, Raf proteins phosphorylate and activate serine and threonine residues on subsequent downstream effector proteins of Ras. Therefore, molecularly targeted agents that interact with multiple signaling pathways/effectors appear to be very promising in the treatment of patients with HCC (Cervello et al. 2012; Cheng et al. 2009). The novel bi-aryl urea sorafenib, an orally available multi-kinase inhibitor, targets kinases of wild-type B-Raf, mutant V559EB-Raf and cRaf, thereby blocking tumor growth (Spangenberg et al. 2008). There are three ras protooncogenes that encode $21 \mathrm{Kd}$ proteins - H-Ras (Harvey murine sarcoma virus), $\mathrm{N}$-Ras (neuroblastoma cell line) and two alternatively spliced K-Ras, K-Ras 4A, and K-Ras 4B; These isoforms are capable of differentially activating various critical effectors, thereby exerting distinct biologic effects. Sorafenib, an inhibitor of receptor tyrosine kinases was found to stabilize the advanced unresectable HCC patients by regulating angiogenesis, and was approved by regulatory agencies in 2007. It has a role on human VEGF receptors-2 and -3 (VEGFR-2/-3) and PDGF- $\beta$ R. However, sorafenib has been also suggested to provide antitumor action in HCC by inhibition of the Raf/MEK/ERK pathway (Llovet and Bruix, 2008 and 2009). Multikinase inhibitor sunitinib is a small molecule that inhibits members of the splitkinase domain family of receptor tyrosine kinase including VEGFR types 1 and 2 (Llovet et al. 2008a). Antiangiogenic effects of sunitinib have been suggested through VEGFR and PDGFR. 
However, a randomized phase 3 study in HCC failed to show a significant survival benefit as compared to sorafenib and study stopped in 2011.

\section{4. mTOR inhibitors}

mTOR inhibitors are potential anti-HCC agents for future (Zhou et al. 2009). Promising mTOR inhibitors are rapamycin and its analogues such as sirolimus, temsirolimus (CCI-779), everolimus (RAD001) and AP23573 (Nocera et al 2008; Rizell et al. 2008). Rapamycin and its analogues such as temsirolimus ( the cell cycle inhibitor) and everolimus and AP23573 (an orally bioavailable derivative of rapamycin) modulate angiogennesis to improve survival of patients in advanced HCC (Heuer 2009, Huynh et al. 2008 ). RAD001, an orally-administered, novel mTOR inhibitor was evaluated in a phase I study (Huynh et al. 2008 and 2008a; Chen et al 2009). Treatment of patients with the combination of rapamycin/ rapamycin-analogue(s) with conventional anticancer drug(s) such as doxorubicin, vinblastine has been found to improve survival in advanced HCC patients (Spangenberg et al. 2008).

\subsection{Proteasome inhibition}

HCC is highly ubiquitinated. The ubiquitination is important to the development and progression of HCC. Proteasome inhibitor such as bortezomib blocks multi-ubiquitinated protein degradation by reversible and competitive inhibition of the active site threonine residue of the 26 S proteasome (Cao and Mao, 2011; Boozari et al. 2009). Antineoplastic activity of bortezomib approved for the treatment of mantle cell lymphoma has already been shown to stabilize advanced HCC in patients (Höpfner et al 2008).

\subsection{Immunomodulatory agents}

An immunomodulator is a substance which has an effect on the immune system. An immunomodulator may be at the same time an immunosuppressant or an immunostimulant and can act on different targets within the immune system. Cell signalling process regulates immune system consisting of immunomodulatory endogenic chemicals and cells. Immunomodulators interfere with the signalling process by shifting the homeostasis of the immune system to reduce or eliminate disease symptoms. Thus these compounds are the obvious choice for therapeutic intervention of HCC. Thymostimulin (a standardized low molecular protein fraction containing thymosin alpha 1 and thymic humoral factor) has been shown to produce cytotoxic immune reaction against HCC. Phase II trials using thymostimulin in patients with advanced and metastasised HCC have shown to control metastatic HCC without predominant side-effects (Dollinger et al. 2010). However, thymostimulin administration in some patients was found to accumulate ascites and cause renal failure (Dollinger et al. 2010).

\subsection{Antisense therapy}

Antisense oligonucleotides offer one approach to target genes involved in cancer progression. They are typically less than 50 nucleotides long and are specifically designed to hybridize to corresponding gene/ mRNA by Watson-Crick binding. They inhibit mRNA function in several 
ways, including modulation of splicing and inhibition of protein translation by disruption of ribosome assembly. Single stranded synthetic nucleic acid (oligonucleotide) when hybridize with DNA or RNA alters transcription or prevents translation thus, preventing or modifying protein production. Because of the volume of information nowadays available on gene sequencing, there has been burst of exploration of capacity for oligomers to inhibit gene/ protein expression. Thus, antisense therapies focus on controlling the production of the proteins on a genetic level. A strand of mRNA is transcribed from DNA, and is a copy of the "coding" or "sense" strand of the gene. The main form of therapy uses the complementary or antisense strand to hybridize the sense strand or mRNA and thus it prevents production of the protein by blocking or altering transcription or translation (Figure 1). With the backbone chemical modifications (in phosphate linkage), antisense oligonucleotides increase resistance to nuclease digestion, prolong their biological half-lives and significantly suppress target-gene expression. Antisense oligonucleotides have been studied for several years as treatments for many diseases and genetic disorders. The therapy is based on the principles of genetic expression. The most widely used modified oligomers in antisense therapies is phosphorothioate oligonucleotides, which have much greater resistance to digestion by nucleases. Phosphorothioate oligonucleotides are rapidly and extensively absorbed and distributed from blood.

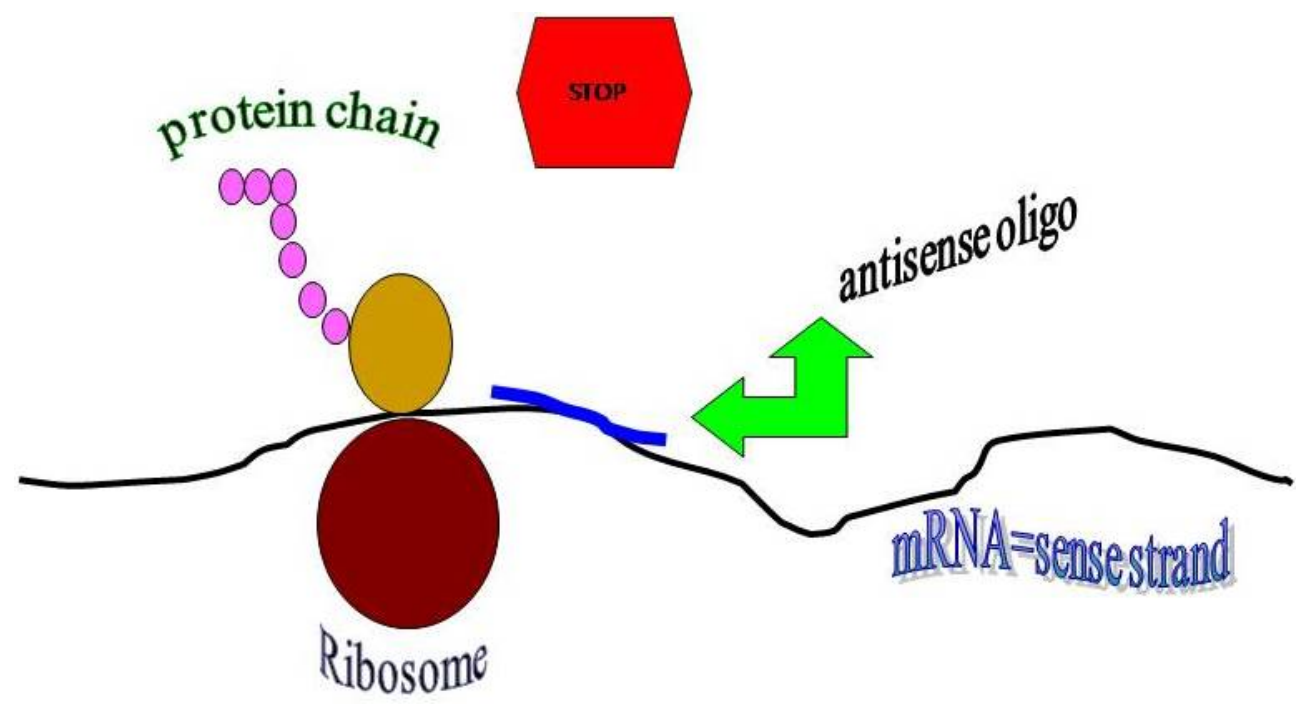

Figure 1. Antisense oligomer-mRNA duplex inhibiting to synthesize peptide chain

The first antisense treatment to get FDA approval to date has been Formivirsen (Vitravene), which is a treatment for cytomegalovirus (CMV) retinitis in people with acquired immunodeficiency disease (AIDS) (Rahman et al. 2008). Several antisense oligonucleotides were shown to target various oncogenes, to overcome tumour escape and to improve therapeutic activity. 
Several studies have shown the anticancer potential of antisense oligonucleotides (Das et al. 2010; Rayburn and Zhang, 2008) and many of them are in clinical trial. They have less cytotoxic side-effects than conventional chemotherapy agents. Systemic treatment with fomivirsen is a milestone in the field of antisense treatment with antisense oligonucleotides. This has led the way for development of antisense oligonucleotides for various new potential targets for the treatment of cancer, including HCC.

\section{Conclusion}

Several experimental evidences have established that targeted inhibition of genes/ proteins involved in controlling HCC growth combined with cytostatic anticancer treatments is a promising approach for HCC therapy. Blocking of single gene/ protein has been found to control neoplastic cellular proliferation in vitro effectively. However, considering the multitude of molecular entities and signalling pathways that regulate the proliferation and the life/death decision in cancer cells, inhibition of a single target gene may not be sufficient to suppress tumor growth. The preclinical/ clinical trials of several potential compounds targeting liver cancerrelevant genes/ proteins may address more specific and adequate future therapies for HCC.

\section{Acknowledgements}

Authors are indebted to the grants from Department of Science Technology (Govt. of India) (DST/Inspire Fellowship/ 2010/ 87) and Indian Council of Medical Research (58/7/2009-BMS) for funding the related projects and findings of which have helped us partially to write this work.

\section{Author details}

Mukherjee Biswajit, Hossain Chowdhury Mobaswar , Bhattacharya Sanchari and Shampa Ghosh

*Address all correspondence to: biswajit55@yahoo.com

Department of Pharmaceutical Technology, Jadavpur University, Kolkata, India

\section{References}

[1] Andreana L, Isgr Ó G, Pleguezuelo M. Surveillance and diagnosis of hepatocellular carcinoma in patients with cirrhosis. World J Hepatol 2009; 1 (1) 48-61. 
[2] Arii S, Sata M, Sakamoto M, Shimada M, Kumada T, Shiina S. Management of hepatocellular carcinoma Report of Consensus Meeting in the 45th Annual Meeting of the Japan Society of Hepatology. Hepatol Res 2010; 40 (7) 667-685.

[3] Asnacios A, Fartoux L, Romano O, Tesmoingt C, Louafi SS, Mansoubakht T. Gemcitabine plus oxaliplatin Gemox combined with cetuximab in patients with progressive advanced stage hepatocellular carcinoma: results of a multicenter phase 2 studies. Cancer 2008; 112 (12) 2733-2739.

[4] Bartolomeo N, Trerotoli P, Serio G. Progression of liver cirrhosis to HCC: an application of hidden Markov model. BMC Med Res Methodol 2011; 11 (38) 1-8.

[5] Bergers G, Hanahan D. Modes of resistance to anti-angiogenic therapy. Nat Rev Cancer 2008; 8 (8) 592-603.

[6] Besaratinia A, Kim SI, Hainaut P, Pfeifer GP. In vitro recapitulating of TP53 mutagenesis in hepatocellular carcinoma associated with dietary aflatoxin B1 exposure. Gastroenterology 2009; 137 (3) 1127-1137.

[7] Bhide RS, Lombardo LJ, Hunt JT. The antiangiogenic activity in xenograft models of brivanib alaninate a dual inhibitor of VEGFR-2 and FGFR-1 kinases. Mol Cancer Ther 2010; 9 (2) 369-378.

[8] Böhm F, Köhler UA, Speicher T, Werner S. Regulation of liver regeneration by growth factors and cytokines. EMBO Mol Med 2010; 2 (8) 294-305.

[9] Boozari B, Wirth T, Woller N, Manns MP, Kubicka S, Kühnel F. Efficacy of HCC treatment with proteasome inhibitor Bortezomib is increased by oncolytic virotherapy mediated downregulation of Mcl-1 and Bip. Z Gastroenterol 2009; 47 3-4.

[10] Bruix J, Sherman M. Management of hepatocellular carcinoma: an update. Hepatology 2011; 53 (3) 1020-1022.

[11] Calvisi DF, Pinna F, Ladu S, Pellegrino R, Simile MM, Frau M. Forkhead box M1B is a determinant of rat susceptibility to hepatocarcinogenesis and sustains ERK activity in human HCC. Gut 2009; 58 (5) 679-87.

[12] Cammà C, Di Marco V, Cabibbo G. Survival of patients with hepatocellular carcinoma in cirrhosis: a comparison of BCLC CLIP and GRETCH staging systems. Aliment Pharmacol Ther 2008; 28 (1) 62-75.

[13] Cao B, Mao X. The ubiquitin-proteasomal system is critical for multiple myeloma: implications in drug discovery. Am J Blood Res 2011; 1 (1) 46-56.

[14] Cao CQ, Yan TD, Bester L, Liauw W, Morris DL. Radioembolization with yttrium microspheres for neuroendocrine tumour liver metastases. Brit J Surg 2010; 97 (4) 537-543.

[15] Carr BI, Kondragunta V, Buch SC, Branch RA. Therapeutic equivalence in survival for hepatic arterial chemoembolization and yttrium 90 microsphere treatments in un- 
resectable hepatocellular carcinoma: a two-cohort study. Cancer 2010; 116 (5) 13051314.

[16] Cavard C, Colnot S, Audard V. Wnt/ $\beta$-catenin pathway in hepatocellular carcinoma pathogenesis and liver physiology. Future Oncol 2008; 4 (5 ) 647-660.

[17] Cervello M, McCubrey JA, Cusimano A, Lampiasi N, Azzolina A, Montalto G. Targeted therapy for hepatocellular carcinoma: novel agents on the horizon. Oncotarget $2012 ; 3$ (3) 236-260.

[18] Cha CH, Saif MW, Yamane BH, Weber SM. Hepatocellular carcinoma: current management. Curr Prob Surg 2010; 47 (1) 10-67.

[19] Chagas AL, Kikuchi LOO, Oliveira CPMS. Does hepatocellular carcinoma in non-alcoholic steatohepatitis exist in cirrhotic and non-cirrhotic patients? Braz J Med Biol Res 2009; 42 (10) 958-962.

[20] Chen JS, Wang Q, Fu XH. Involvement of PI3K/PTEN/AKT/mTOR pathway in invasion and metastasis in hepatocellular carcinoma: association with MMP-9. Hepatol Res 2009; 39 (2) 177-186.

[21] Cheng AL, Kang YK, Chen Z, Tsao CJ, Queen S, King JS. Efficacy and safety of sorafenib in patients in the Asia-Pacific region with advanced hepatocellular carcinoma: a phase III randomised double-blind placebo-controlled trial. Lancet Oncol 2009; 10 (1) $25-34$.

[22] Chung H, Kudo M, Takahashi S. Comparison of three current staging systems for hepatocellular carcinoma: Japan integrated staging score new Barcelona Clinic Liver Cancer staging classification and Tokyo score. J Gastroen Hepatol 2008; 23 (3) 445452.

[23] Das T, Patra F, Mukherjee B. Effect of antisense oligomer in controlling c-raf1 overexpression during diethylnitrosamine-induced hepatocarcinogenesis in rats. Cancer Chemother Pharmacol 2010; 65 (2) 309-318.

[24] Desbois-Mouthon C, Baron A, Blivet-Van Eggelpoël MJ. Insulin-like growth factor-1 receptor inhibition induces a resistance mechanism via the epidermal growth factor receptor/ HER3/AKT signaling pathway: rational basis for cotargeting insulin-like growth factor-1 receptor and epidermal growth factor receptor in hepatocellular carcinoma. Clin Cancer Res 2009; 15 (17) 5445-5456.

[25] Dollinger MM, Lautenschlaeger C, Lesske J, Tannapfel A, Wagner AD, Schoppmeyer K. Thymostimulin versus placebo for palliative treatment of locally advanced or metastasised hepatocellular carcinoma: a phase III clinical trial. AIO Hepatobiliary Study Group BMC Cancer 2010; 24 (10) 457-467.

[26] Forner A, Reig ME, de Lope CR, Bruix J. Current strategy for staging and treatment: the BCLC update and future prospects. Semin Liv Dis 2010; 30 (1) 61-74. 
[27] Frau M, Biasi F, Feo F, Pascale RM. Prognostic markers and putative therapeutic targets for hepatocellular carcinoma. Mol Aspects Med 2010; 31 (2) 179-193.

[28] Friedman SL. Hepatic stellate cells: protean multifunctional and enigmatic cells of the liver. Physiol Rev 2008; 88 (1) 125-172.

[29] Garrett C, Siu L, El-Khoueiry A. A phase I study of brivanib alaninate BMS-582664 an oral dual inhibitor of VEGFR and FGFR tyrosine kinases in combination with fulldose cetuximab in patients with advanced gastrointestinal malignancies who failed prior therapy. J Clin Oncol 2008; 26 suppl:abstr 4111.

[30] Gauler TC, Besse B, Mauguen A, Meric JB, Gounant V. Phase II trial of PTK787/ZK 222584 vatalanib administered orally once-daily or in two divided daily doses as second-line monotherapy in relapsed or progressing patients with stage IIIB/IV nonsmall-cell lung cancer NSCLC. Ann Oncol 2012; 23 (3) 678-687.

[31] Gomaa AI, Khan SA, Toledano MB, Waked I,Taylor-Robinson SD. Hepatocellular carcinoma: epidemiology risk factors and pathogenesis. World J Gastroentrol 2008; 14 (27) 4300-4308.

[32] Gomaa AI, Khan SA, Leen ELS, Waked I, Taylor-Robinson SD. Diagnosis of hepatocellular carcinoma. World J Gastroentrol 2009; 15 (11) 1301-1314.

[33] Gouas DA, Shi H, Hautefeuille AH. Effects of the TP53 pR249S mutant on proliferation and clonogenic properties in human hepatocellular carcinoma cell lines: Interaction with hepatitis B virus X protein. Carcinogenesis 2010; 31 (8) 1475-1482.

[34] Hadziyannis SJ. Natural history of chronic hepatitis B in Euro-Mediterranean and African countries. J Hepatol 2011; 55 (1) 183-191.

[35] Heuer M, Benko T, Cicinnati VR, Kaiser GM, Sotiropoulos GC, Baba HA. Effect of low-dose rapamycin on tumor growth in two human hepatocellular cancer cell lines. Transplant Proc 2009; 41 (1) 359-365.

[36] Hironaka S, Onozawa Y, Aramaki T. Phase 1 study of brivanib alaninate a novel FGF and VEGF receptor inhibitor. Japanese Society for Clinical Oncology JSCO Annual Conference Yokohama October 2009; 22- 24 abstr OS036-3.

[37] Höpfner M, Schuppan D, Scherübl H. Growth factor receptors and related signalling pathways as targets for novel treatment strategies of hepatocellular cancer. World J Gastroenterol 2008; 14 (1) 1-14.

[38] Hoshida Y, Villanueva A, Kobayashi M, Peix J, Chiang DY, Camargo A. Gene expression in fixed tissues and outcome in hepatocellular carcinoma. N Engl J Med 2008; 359 (19) 1995-2004.

[39] Hoshida Y, Villanueva A, Llovet JM. Molecular profiling to predict hepatocellular carcinoma outcome. Expert Rev Gastroenterol Hepatol 2009; 3 (2) 101-103. 
[40] Huynh H, Chow KP, Soo KC, Toh HC, Choo SP, Foo KF. Rad001 (Everolimus) inhibits tumor growth in xenograft models of human hepatocellular carcinoma. J Cell Mol Med 2009; 13 (7) 1371-1380.

[41] Huynh H, Ngo VC, Fargnoli J. Brivanib alaninate a dual inhibitor of vascular endothelial growth factor receptor and fibroblast growth factor receptor tyrosine kinases induces growth inhibition in mouse models of human hepatocellular carcinoma. Clin Cancer Res 2008a; 14 (19) 6146-6153.

[42] Iavarone M, Colombo M. HBV-related HCC clinical issues and therapy. Digest Liver Dis 2011; 43 supplement 1 S32-S39.

[43] Kaseb AO, Garrett-Mayer E, Morris JS, Xiao L, Lin E, Onicescu G. Efficacy of Bevacizumab plus Erlotinib for advanced hepatocellular carcinoma and predictors of outcome: final results of a phase II trial. Oncology 2012; 82 (2) 67-74.

[44] Kew MC. Epidemiology of chronic hepatitis B virus infection hepatocellular carcinoma and hepatitis B virus-induced hepatocellular carcinoma. Pathol Biol 2010; 58 (4) 273-277.

[45] Kopetz S, Hoff PM, Eng MJ. Angiogenic cytokines are increased prior to disease progression in metastatic colorectal cancer patients treated with bevacizumab. ASCO Gastrointestinal Cancers Symposium San Francisco January 15-17 2009; abstr 292.

[46] Lachenmayer A, Alsinet C, Chang CY, Llovet JM. Molecular approaches to treatment of hepatocellular carcinoma. Digest Liver Dis 2010; 42(3) 264-272.

[47] Levêque D. Pharmacokinetics of gefitinib and erlotinib. Lancet Oncol 2011; 12 (12) 1093.

[48] Lim SG, Mohammed R, Yuen MF, Kao JH. Prevention of hepatocellular carcinoma in hepatitis B virus infection. J Gastroenterol Hepatol 2009; 24 (8) 1352-1357.

[49] Llovet JM, Bruix J. Molecular targeted therapies in hepatocellular carcinoma. Hepatology 2008; 48 (4) 1312-1327.

[50] Llovet JM, Bruix J. Testing molecular therapies in hepatocellular carcinoma: the need for randomized phase II trials. J Clin Oncol 2009; 27 833-835.

[51] Llovet JM, Ricci S, Mazzaferro V, Hilgard P, Gane E, Blanc JF. Sorafenib in advanced hepatocellular carcinoma. N Engl J Med 2008a; 359 (4) 378-390.

[52] Masuzaki R, Yoshida H, Tateishi R, Shiina S, Omata M. Hepatocellular carcinoma in viral hepatitis: improving standard therapy. Best Pract Res 2008; 22 (6) 1137-1151.

[53] Miller AA, Murry DJ, Owzar K, Hollis DR, Kennedy EB, Abou-Alfa G. Phase I and pharmacokinetic study of sorafenib in patients with hepatic or renal dysfunction: CALGB 60301. J Clin Oncol 2009; 27 (11) 1800-1805. 
[54] Nocera A, Andorno E, Tagliamacco A, Morelli N, Bottino G, Ravazzoni F. Sirolimus therapy in liver transplant patients: an initial experience at a single center. Transplant Proc 2008; 40 (6) 1950-1952.

[55] Orlando A, Leandro G, Olivo M, Andriulli A, Cottone M. Radiofrequency thermal ablation vs percutaneous ethanol injection for small hepatocellular carcinoma in cirrhosis: meta-analysis of randomized controlled trials. Am J Gastroenterol 2009; 104 (2) 514-524.

[56] Philip P, Mahoney M, Allmer C, Thomas J, Pitot H, Kim G. Phase II study of Erlotinib (OSI-774) in patients with advanced hepatocellular cancer. J Clin Oncol 2005; 23 (27) 6657-6663.

[57] Pinter M, Sieghart W, Graziadei I, Vogel W, Maieron A, Konigsberg R. Sorafenib in unresectable hepatocellular carcinoma from mild to advanced stage liver cirrhosis. Oncologist $2009 ; 14$ (1) 70-76.

[58] Rahman SMA, Seki S, Obika S, Yoshikawa H, Miyashita K, Imanishi T. Design synthesis and Properties of 2', 4'-BNA ${ }^{\mathrm{NC}}$ : a bridged nucleic acid analogue. J Am Chem Sc 2008; 130 (14) 4886-4896.

[59] Raphael SW, Yangde Z, Xiang CY. Hepatocellular carcinoma: focus on different aspects of management. ISRN Oncology 2012; 2012 1-12.

[60] Rayburn ER, Zhang R. Antisense RNAi and gene silencing strategies for therapy: mission possible or impossible? Drug Discov Today 2008; 13 (11-12) 513-521.

[61] Rizell M, Andersson M, Cahlin C, Hafstrom L, Olausson M, Lindner P. Effects of the mTOR inhibitor sirolimus in patients with hepatocellular and cholangiocellular cancer. Int J Clin Oncol 2008; 13 (1) 66-70.

[62] Roncalli M, Park YN, di Tommaso L. Histopathological classification of hepatocellular carcinoma. Digest Liver Dis 2010; 42 (3) 228-234.

[63] Rosen HR. Clinical practice chronic hepatitis C infection. N Engl J of Med 2011; 364 (25) 2429-2438.

[64] Shariff MIF, Cox IJ, Gomaa AI, Khan SA, Gedroyc W, Taylor-Robinson SD. Hepatocellular carcinoma: current trends in worldwide epidemiology risk factors diagnosis and therapeutics. Expert Rev Gastroenterol Hepatol 2009; 3 (4) 353-367.

[65] Sherman M. Epidemiology of hepatocellular carcinoma. Oncology 2010; 78 (1) 7-10.

[66] Sherman M. Hepatocellular carcinoma: screening and staging. Clin Liver Dis 2011; 15 (2) 323-334.

[67] Siegel AB, Cohen EI, Ocean A, Lehrer D, Goldenberg A, Knox JJ. Phase II trial evaluating the clinical and biologic effects of bevacizumab in unresectable hepatocellular carcinoma. J Clin Oncol 2008; 24 (26) 2992-2998. 
[68] Siegel AB, McBride RB, El-Serag HB, Hershman DL, Brown Jr RS, Renz JF. Racial disparities in utilization of liver transplantation for hepatocellular carcinoma in the United States 1998-2002. Am J Gastroenterol 2008a; 103 (7) 120-127.

[69] Simile MM, Frau M, Pascale RM, Feo F. New putative prognostic markers and therapeutic targets for the molecular approach to treatment of hepatocellular carcinoma. J Exp Integr Med 2011; 1 85-97.

[70] Sonja K, Olsen RS, Brown JR, Siegel AB. Review: Hepatocellular carcinoma: review of current treatment with a focus on targeted molecular therapies. Therap Adv Gastroenterol 2010; 3 (1) 55-56.

[71] Spangenberg HC, Thimme R, Blum HE. Evolving therapies in the treatment of hepatocellular carcinoma. Biologics 2008; 2 (3) 453-462.

[72] Takigawa Y, Brown AM. Wnt signaling in liver cancer. Curr Drug Targets 2008; 9 (11) 1013-1024.

[73] Thomas MB, Chadha R, Glover K, Wang X, Morris J, Brown T. Phase 2 study of erlotinib in patients with unresectable hepatocellular carcinoma. Cancer 2007; 110 (5) 1059-1067.

[74] Thomas MB, O'Beirne JP, Furuse J, Chan ATC, Abou-Alfa G Johnson P. Systemic therapy for hepatocellular carcinoma: cytotoxic chemotherapy targeted therapy and immunotherapy. Ann Surg Oncol 2008; 15 (4) 1008-1014.

[75] Thomas MB, Morris JS, Chadha R, Iwasaki M, Kaur H, Lin E. Phase II trial of the combination of bevacizumab and erlotinib in patients who have advanced hepatocellular carcinoma. J Clin Oncol 2009; 27 (6) 843-850.

[76] Woo HG, Park ES, Cheon JH, Kim JH, Lee JS, Park BJ. Gene Expression-based recurrence prediction of hepatitis B virus-related human hepatocellular carcinoma. Clin Cancer Res 2008; 14 (7) 2056-2064.

[77] Wu JY, Wu SG, Yang CH, Chang YL, Chang YC, Hsu YC, Shih JY, Yang PC. Comparison of gefitinib and erlotinib in advanced NSCLC and the effect of EGFR mutations. Lung cancer 2011; 72 (2) 205-212.

[78] Yang JD, Roberts LR. Epidemiology and management of hepatocellular carcinoma infectious disease. Clin N Am 2010; 24 (4) 899-919.

[79] Zhang XF, Yu L, Lu Y. Wnt/ $\beta$-catenin signaling pathway and its role in hepatocellular carcinoma. Front Med China 2008; 2 (3) 216-228.

[80] Zhou L, Huang Y, Li J, Wang Z. The mTOR pathway is associated with the poor prognosis of human hepatocellular carcinoma. Med Oncol 2009; 27(2) 255-261.

[81] Zhu AX, Duda DG, Sahani DV, Jain RK. HCC and angiogenesis: possible targets and future directions. Nat Rev Clin Oncol 2011; 8 (5) 292-302. 
[82] Zhu AX. Development of sorafenib and other molecularly targeted agents in hepatocellular carcinoma. Cancer 2007; 112 (2) 250-259. 
